OF PSYCHOLOGY

IN THE $21^{\text {st }}$ CENTURY

Vol. 13, No. 2, 2019

\title{
PERSONAL VALUES AND SELF- ACCEPTANCE: ANXIETY FREE VS ANXIETY-BASED DIMENSION
}

\author{
Mariam Kvitsiani, Maia Mestvirishvili, \\ Khatuna Martskvishvili, Tamar Kamushadze, \\ Mariam Odilavadze, Mariam Panjikidze \\ Ivane Javakhishvili Tbilisi State University, Georgia \\ E-mail: Mariam.kvitsiani768@pes.tsu.edu.ge; maia.mestvirishvili@tsu.ge khatuna. \\ martskvishvili@tsu.ge; tamar.kamushadze840@pes.tsu.edu.ge; mariami.odila- \\ vadze233@pes.tsu.edu.ge; marika.panjikidze@tsu.ge
}

\begin{abstract}
When talking about human well-being, Unconditional Self-acceptance represents one of the cores. Although researchers have focused on various predictors of Acceptance, there is not a clear understanding of personal values impacting the process of accepting oneself. The aim of the research was to explore the association between basic values and unconditional self-acceptance, and to find out the role of psychological flexibility in this relationship. 370 participants filled the questionnaires to explore basic values, unconditional self-acceptance and psychological flexibility. As data showed, self-transcendence and openness to change predict higher level of psychological flexibility, however, only openness to change possesses positive predictive power for unconditional self-acceptance. Mediation model indicates that basic value system of openness to changes is the one, which reflected on individual's higher psychological flexibility, and through this flexibility she/he achieves higher level of unconditional self-acceptance. The research confirmed a unique role of openness to change in association with self-acceptance which might be an important insight for clinical psychologists as well as for mental health professionals.
\end{abstract}

Keywords: basic value systems, psychological flexibility, quantitative research, unconditional selfacceptance.

\section{Introduction}

Third Wave behavioral and cognitive interventions focus on individual's ongoing experiences and increasing acceptance (Hayes, 2004), which leads to the ability to enjoy more and be less stressed due to these experiences (Hayes, Follette, \& Linehan, 2011). This process is known as unconditional self-acceptance, which implies to take oneself unconditionally and entirely, without referring on whether one's behaviors are wise, competent and whether she/ he is respected and/or loved by others (Dryden \& Neenan, 2004; Ellis, 1997).

Existing research has focused on the association of self-acceptance with mental health, mindfulness, and perfectionism (Carson \& Langer, 2006; Chamberlain \& Haaga, 2001.; Falkenstein \& Haaga, 2013; Stankovic, Matic, Vukosavljevic-Gvozden, \& Opacic, 2015; Thompson 
\& Waltz, 2008), however, none of the studies explore interrelation between individual's basic values and self-acceptance. Given that values define and direct individual's attitudes and behaviors (Rokeach, 1973), it is logical to assume that growth-oriented values, such as Openness to Change and Self-transcendence leading to less anxiety, are associated with Self-acceptance. The presented study seeks to understand the connection between person's basic values and self-acceptance.

The definition of values intuitively suggests that the value system influences all aspects of individual's functioning. Does this automatically imply that value orientation defines the process of self-perception and the way the person relates to himself/herself? If values serve as the benchmark individual follows to decide what is right, important or appreciated for her/him, we can assume that it also defines the way individual thinks of herself/himself and whether she/he accepts herself/himself as it is.

Past research suggested that Self-acceptance is tightly linked to cognitive and behavioral flexibility (Jeffcoat \& Hayes, 2013, cited in Bernard, 2013). Therefore, flexibility is discussed as a supportive factor in association between value system and self-acceptance. Study assumes that particular value systems support psychological flexibility which, in turn, is the process enabling the individual to experience variety of her/his the environment, gain different experiences and, at the same time, constantly stay in touch with her/his inner state (Maor, Ben-Itzhak, 2014). The latter impacts the degree of self-acceptance.

In this article we aim to reveal whether values have the power to influence self-acceptance and explore the role of psychological flexibility in this relationship.

\section{Unconditional Self-acceptance}

Unconditional self-acceptance implies that personality accepts herself/himself entirely and unconditionally unrelated to that whether her/his actions are wise, correct or competent and whether she/he is respected and loved by others (Ellis, 1997).

The construct of unconditional self-acceptance is borrowed from rational-emotional behavioral therapy (REBT), which encompasses existence/non-existence of the self-evaluation or, in other words, evaluation of self-worthiness. REBT suggests that this always leads towards negative outcomes (depression, anxiety), because global self-worth always depends on meeting some standards (for instance, perfectionistic standards) which are not always implementable. On the other hand, Unconditional Self-acceptance implies evaluation of one's own deeds and not evaluation of self-worth (Ellis, 1994). Therefore, it is seen as a suppressor factor of various difficulties. Unconditional Self-acceptance is a main focus of Acceptance and Commitment Therapy as well, which has already proved its effectiveness in solving personal problems of different levels of difficulty (Ruiz, 2012), underlines important role of psychological flexibility and implies conscious involvement in the present moment as it is given and not as a person thinks about it (Hayes, Strosahl, \& Wilson, 2012).

Thompson and Waltz (2008) showed that people learn to accept their thoughts, emotions and situations through mindfulness, as well as not to resist unchangeable things and being nonjudgmental based on others' opinions. Chamberlain and Haaga (2013) suggested that there is a positive association between Unconditional Self-acceptance and self-esteem, nonetheless they note the existing conceptual difference between these two constructs.

Although studies linking Self-acceptance with other personal constructs is not vast, construct similarities can be found with level of acceptance in general, which once more proved its importance for individual's well-being.

In definition of the concept of acceptance (Brown, 1993; Weiner \& Simpson, 1991) researchers consider the following issues: (1) Stimulus is perceived as desirable and acceptable experience that might be the mean to satisfy particular need or obligation; (2) To respect, to accept and to see the event in desirable light; (3) To agree or being convinced in something, and (4) Agreeableness.

This understanding of acceptance closely relates to understanding of tolerance (Weiner 
OF PSYCHOLOGY

IN THE $21^{\text {st }}$ CENTURY Vol. 13, No. 2, 2019

\& Simpson, 1991), as both refer to the ability to accept unpleasant actual state and try to improve it and the disposition to be patient towards others' opinion and behaviors and to accept them (e.g., Ellis \& Robb, 1994; Fruzetti \& Iverson, 2004; Greenberg, 1994).

Acceptance is not the same as hostile or submissive tolerance that is not connected to health-related positive outcomes (Cook \& Hayes, 2010). Research has showed that conscious resistance of the complex and negative thoughts, emotions or experiences intensifies these experiences and the person becomes more sensitive and reactive to them. Hence, individual experiences less positive affect (Chawla \& Ostafin, 2007; Hayes et al., 2006; Sloan, 2004). Acceptance does not imply accepting either potentially changeable situations or the situations, when change is associated with enhancement of the quality of life (Follette \& Pistorello, 2007).

Acceptance requires to be tolerant to the given experience. In order to be aware of current condition, even though this condition is unpleasant, the person should be in touch with reality and to decrease the rate of avoidant behaviors. Accordingly, tolerance can be conceptualized as involvement in the ongoing experience, regardless the nature of this experience (Wlliams, C. \& JayLynn S, 2010).

It must be noted that when speaking about Unconditional Self-acceptance and Psychological Flexibility, nonjudgmental state, which implies considering and discussing any experience, behavior or event in non-evaluative category, is the central concept they have in common (Germer, 2005; Hayes, 2004).

Being nonjudgmental (Germer, 2005; Hayes, 2004; Peterson, 1994) and mindful is the central issue in conceptualizing the acceptance (Baer, 2006; Dimidjian \& Linehan, 2003;). Being nonjudgmental is defined as to restrain oneself from categorizing things and label things as good-or-bad (Cordova \& Kohlenberg, 1994), correct-or-incorrect (Hayes, 1994; Linehan, 1994). This issue is often targeted in therapy (REBT; David, Lynn, Ellis, 2009), since such beliefs are associated with emotional outcomes leading to dysfunctional behaviors (Beck, Emery, \& Greenberg, 1996; Ellis \& Robb, 1994).

\section{Basic Values}

Values express individual's choice and actions (Higgins, 2006), basic motivations (Schwartz, 1992), internalization of social institutions (Rokeach, 1973), and culturally shared significant systems (Geertz, 1973). Large number of studies have showed, that basic value systems might vary on the cultural or social system level, as well as on the individual level.

Personal values are always associated with personality traits (Roccas, Sagiv, Schwartz, \& Knafo, 2002), attitudes and behaviors (Bardi \& Schwartz, 2003). Such a view of the values underlines their variability on individual level.

Values are structurally interconnected in one total system based on their relative importance. Such system tends to be stable and enables us to predict the behavior of the individual or society (Schwartz, 2012).

Schwartz (2012) conceptualized ten universal values and described them alongside two dimensions: (1) Openness to Changes vs. Conservation and (2) Self-enhancement vs Selftranscendence. The structure of the dimensions follows two basic principles. One of them is interest, which the values serve. In this regard, Schwartz (2012) differentiated values reflecting personal vs. social interests. Personal interests, otherwise called Self-enhancement values, are reflected in values of achievement, power, hedonism, stimulation and self-management. As for social interests, they are known as Self-transcendence values and consist of safety, conformity, tradition, universalism and benevolence (Schwartz 2012:12).

Studies have proved that values are associated with social interests. Lönnqvist and colleagues (2013) explored the interrelation of values and prosocial behavior and revealed predictive power of universalism for higher level of prosocial behavior, whereas power reliably predicted lower levels of it. Similar data were obtained from other study (Batson, Eklund, Chermok, Hoyt, and Ortiz, 2007) signifying individual differences in attitudes towards other's well-being. Researchers suggested, that value of benevolence increases the ability to see the 
need of another person and other person's perspective, empathy, and care. Universalism acts likewise in relation to out group; However, values of Self-enhancement have opposite impact (Silfver, Helkama, Lonnqvist, \& Verkasalo, 2008).

The second principle of value organization is anxiety (Schwartz, 2012). Here are two groups of values: Values containing anxiety, so called self-defense values - Conservation and Self-enhancement, and anxiety free values that are directed on growth and self-development Openness to change and Self-transcendence.

Value of Achievement (Schwartz, 1992) is connected to revealing the competence that is time and energy consuming, and in turn, leads to the stress and the symptoms of depression. Contrary to this, Benevolence and Universalism negatively relates to stress and depression symptoms (Thoits \& Hewitt, 2001). Hibbing and colleagues (2014) empirically proved, that politicians prioritize conservative values (Piurko et al. 2011) through which they suggest their higher sensitivity towards negative stimuli. Tritt, Inzlicht, and Peterson (2014) claim that, in general, conservatives have lower arousal threshold and are more sensitive to the stimulation. Accordingly, those who prefer conservative values, in contrary to the persons with values of Openness to Change, could be physiologically more sensitive to any (negative included) stimulation (Schwartz, 2014). Research also suggest the positive correlation between conservatism and different types of anxiety (for instance, death anxiety and fear of threat and loss) (Jost, Kruglanski, Glaser, \& Sulloway, 2003.).

Another study has validated this finding (Schwartz et al., 2000) by showing that agreement with statements reflecting micro-concerns such as personal health condition, safety, social acceptance, success, financial condition, etc., are positively associated with anxiety. Moreover, values of Self-enhancement and Hedonism are positively correlated with microconcerns, whilst Self-transcendence and Self-acceptance are negatively associated with micro-concerns.

Values also define the attitudes and the ways the person behaves toward others. Mikulincer and colleagues (2003) showed that values define both, the degree of avoidant attitude and that this attitude is emerged upon distrust of others and restraining from close relationships. Moreover, Openness to Changes is positively associated with positive view of human nature and it turned out to be in negative correlation with Self-enhancement and Conservation (Mikulincer et al. 2003). Caprara \& Steca (2007) suggest that values of Selftranscendence positively reflected on self-efficacy and showed that this is true in several directions: the beliefs in ability to manage negative and positive affect, to manage social relationships, and sense other feelings.

\section{Psychological Flexibility}

Presented research proposes the Psychological Flexibility as the cognitive mechanism to explain the relationship between Basic Values and Unconditional Self-acceptance.

Psychological Flexibility is seen as both, intra- and interpersonal process and supports adaptation to any change (Kashdan \& Rottenberg, 2010). The quest for different and changeable experiences is an active process and is preserved as a positive experience for those who score higher on Psychological Flexibility (Maor \& Ben-Itzhak, 2014). The ability to adapt closely associates with the usage and regulation of emotions in changeable situations in the ways, such as to retain, decrease or increase positive or negative affect. Flexible emotional pattern enhances the adaptive potential of personality, which in turn, reflects on well-being (Matsumoto \& LeRoux, 2007).

Psychological Flexibility requires openness to experience emerging from either internal or external stimuli. If individual is open, curious and absorbs novelty with ease, she/he looks for and gains new experience and knowledge (Izard, 1977; McCrae \& Costa, 1997). Such individual is open for both, positive and negative experiences coming from new, complex, ambiguous and unpredictable challenges (Kashdan \& Silvia, 2009). Open and curios personality searches for the means to find the meaning in her/his own behaviors and this, in turn, 
reflects on Self-enhancement (Higgins, 2006; Kashdan \& Steger, 2006;). The sense of the self remains flexible if the person is eager to broaden and search for the experiences. Longitudinal studies on psychological health have underlined the significance of the openness to experiences in transitional periods in person's life (Helson \& Srivastava, 2001). The person who is open to experience considers different perspectives and, therefore, is more adaptive in finding alternatives for overcoming obstacles in pursuing his/her own goals (King \& Hicks, 2007).

As research showed, out of personality traits, only openness to experience is associated with creativity and divergent thinking in stressful situation (Chamorro-Premuzic \& Reichenbacher, 2008). Researchers found that openness to experience in stressful situations is correlated with higher score on tolerance and compassion (O'Brien \& DeLongis, 1996). Higher score on ego-flexibility is correlated with curiosity, vitality and quest, creativity, coping with stress and various challenges (Klohnen, 1996). These findings are supported by other studies showing that higher score on self-determination, search for novelty and diversity, and curiosity are linked with well-being, whilst the latter negatively associated with conformism, obedience and stability (Sagiv \& Schwartz, 2000). Also, DeYoung and colleagues (2002) suggest that conformity positively correlates with stability and is negatively connected with flexibility. Another study (DeYoung, 2006) reveals that openness expresses the tendency to flexibly be involved in novelties behaviorally as well as cognitively. This corresponds to the motivational goals, which are served by values of openness to experience.

The importance of openness for Psychological Flexibility is well manifested in the studies focusing on the need for clarity and intolerance to uncertainty (Kruglanski \& Webster, 1996; Sorrentino \& Roney, 2000). Stronger need for clarity on people or situations and sense of accuracy increases stereotypicality, conformity and dogmatism. Besides, research showed that Psychological Flexibility was linked to mental health and well-being. The mechanism is as follows: Psychological Flexibility enables one to have access to his/her internal and external needs which, in turn, facilitates the process of adaptation to the environment (cf. McCracken, Gutierrez-Martinez, \& Smyth, 2013). On the one hand, it strengthens the ability to recognize and to regulate emotions and thoughts (Landstra, Ciarrochi, Deane, \&Hillman, 2013), and on the other hand, it increases individual's ability to shift attention and be focused on changeable circumstances (Galatzer-Levy, Burton, \& Bonanno, 2012). The linkage of Psychological Flexibility to mental health and adaptation is empirically proven through the longitudinal and cross-sectional studies (Galatzer-Levy, Burton \& Bonanno, 2012; Landstra, Ciarrochi, Deane, \& Hillman, 2013).

There is the body of research on Psychological Flexibility and health, revealing that lower score on flexibility is associated with various manifestations of the psychopathology, such as cognitive rigidity expressed via rumination and anxiety (Nolen-Hoeksema, Wisco, \& Lyubomirsky, 2008), perseverations of behavioral patterns, as well as difficulties in coping with stressful events and problems associated with future planning and goals (e.g., Bonanno, Papa, Lalande, Westphal, \& Coifman, 2004).

Given all above spoken, we assume that anxiety free values, such as Self-transcendence and Openness to change are reflected on higher score on Unconditional Self-acceptance and this connection is mediated by Psychological Flexibility. In other words, open systems and growth-oriented values provide more resource for Psychological Flexibility that, in turn, is reflected on Unconditional Self-acceptance.

\section{Research Aim}

The research aimed to explore the association between basic values and unconditional self-acceptance, and to describe the role psychological flexibility plays in this association.

It was hypothesized that anxiety free values, such as Self-transcendence and Openness to Change, should be reflected on higher scores of Self-acceptances, whist the values incorporating anxiety and oriented on self-defense - Conservation and Self-enhancement - should be leading towards lower score of Self-acceptance. Besides, we assume Psychological Flex- 
ibility to be one of the explanatory mechanisms for these associations: anxiety-free values that enable individual to gain various experiences and be growth-oriented, should serve as prerequisites for Psychological Flexibility. These, in turn, should be leading towards higher level of Unconditional Self-acceptance.

\section{Research Methodology}

\section{General Description}

The research was carried out in Georgia, Tbilisi, based on convenient sampling method. Basic Quantitative method design was used in order to identify associations among variables in question. Time frame for the research was defined as of three months. Most of the field work was done on the basis of Ivane Javakhishvili Tbilisi State University, Tbilisi, Georgia.

\section{Research Participants}

In order to ensure statistical reliability of the results, based on the number of items and scales used, three hundred seventy people were recruited for the research. Of all participants 268 were female. Age range was as follows: 18-25 (43\%), 26-35 (26\%), 36-45 (12\%), 46-55 (11\%) and more than 56 years old (7\%).

\section{Ethical Procedures}

As national research ethics committee is not yet functioning in the country, all procedures performed in the research involving human participants were approved by Ivane Javakhisvhili Tbilisi State University, Science and Research department. The study has been performed in accordance with 1964 Helsinki declaration and its later amendments or comparable ethical standards.

\section{Informed Consent}

The participation in the study was voluntary and participants did not get any incentives. The aim of the research was explained shortly before the assignment. Participants were warned about the approximate time and effort they would have to put in their participation. Verbal consent was obtained from all participants before distributing the questionnaires. After obtaining informed consent, participants were provided with self-report questionnaires with the standard instructions and were asked to complete them in the intended order. The procedure was carried out individually with each participant and was observed by the interviewer.

\section{Instruments}

Basic Values. Georgian version (Makashvili, 2017) of the Schwarz Values Questionnaire was used (Schwarz, 2012) to measure basic values. It consists of 57 items and measures 19 values ( 3 items per value). Respondents are asked to indicate for each of the statement how much like him/her is the other person described in the statement. Responses range from "very much like me" (6) to "not like me at all" (1).

Psychological Flexibility was measured via Georgian version (Kvitsiani, Mestvirishvili, 2016) 20-item self-report questionnaire (Ben-Itzhak \& Bluvstein, 2014). Each of the statements (such as, "It's easy for me to think of ways of conduct that are very unconventional" and "At times I can make significant decisions, based on my need to change") measure the degree of openness, adaptability and flexibility of the personality in the situation and how much she/he considers both, internal and external stimuli. Respondents had to give their answers on 6-point Likert scale, ranging from 1 ("Fully not corresponds to the reality") to 6 ("Fully corresponds to the reality") 
OF PSYCHOLOGY

IN THE $21^{\text {st }}$ CENTURY Vol. 13, No. 2, 2019

Unconditional Self-Acceptance was measured by Georgian Version (Kvitsiani, Mestvirishvili 2016) of self-reported questionnaire (USAQ; Chamberlain \& Haaga, 2001a), consisting of 20 items (such as for instance, "Being praised makes me feel more valuable as a person" and "My sense of self-worth depends a lot on how I compare with other people") and measuring the degree of importance to meet criteria in order to accept oneself. For each of the statements, respondents were asked to indicate the degree to which statement is true, using the 7-point Likert format scale, whereas 1 corresponded to "Almost always it is not true" and 7 - "Almost always it is true".

Each research participant received self-report questionnaires with the same sequence (basic values, psychological flexibility, Unconditional Self-acceptance) and instructions. There was no time limit for completion of the questionnaire.

\section{Data Analysis}

Data analysis consisted of four steps. First, analyses of variance and Independent t-test was used to show the differences according to age and gender. Second, correlational matrix was built to see any associations among variables. Based on the hypotheses, multiple hierarchical regression was conducted, in order to check the predictive role of independent variables. And lastly, meditational analysis was applied to illustrate the process among variables in question; Basic analysis was performed with IBM SPSS 21 statistics data editor, for mediational analyses PROCESS v.3.0 by Hayes was used.

\section{Research Results}

\section{Age Groups}

Statistically significant difference by age groups was revealed in case of Openness to Change $(F(4,360)=4.38, p=.002)$ and Conservation $(F(4,360)=7.09, p=.0001)$ (Table 1). Results show that mean score on Openness to Change for 18-25 years old research participants significantly exceeds mean score on the same scale showed by $46-55$ years old participants. As for Conservation, the youngest age group has significantly lower mean score than all others.

Age groups differed by Psychological Flexibility $(F(4,360)=2.98, p=.019)$ and Self-acceptance $(F(4,360)=3.94, p=.004)$. in both cases the youngest group scores are significantly lower than those who are beyond 56 .

Table 1. One-way ANOVA for target variables by age.

\begin{tabular}{|c|c|c|c|c|c|c|c|c|c|c|c|c|}
\hline \multirow{2}{*}{ Values } & \multicolumn{2}{|c|}{$18-25$} & \multicolumn{2}{|c|}{$26-35$} & \multicolumn{2}{|c|}{$36-45$} & \multicolumn{2}{|c|}{$46-55$} & \multicolumn{2}{|c|}{$56+$} & \multirow{2}{*}{$p$} & \multirow{2}{*}{$\begin{array}{c}\text { Tukey's } \\
\text { HSD }\end{array}$} \\
\hline & $M$ & $S D$ & $M$ & $S D$ & M & $S D$ & $M$ & $S D$ & M & $S D$ & & \\
\hline Openness & 19.4 & 2.5 & 18.6 & 2.8 & 18.2 & 2.7 & 17.8 & 3.0 & 18.4 & 2.5 & .002 & $1>4$ \\
\hline Conservation & 22.2 & 3.0 & 23.6 & 3.9 & 24.3 & 3.2 & 23.8 & 3.8 & 24.8 & 2.9 & .000 & $1<2,3,4,5$ \\
\hline $\begin{array}{l}\text { Psychological } \\
\text { Flexibility }\end{array}$ & 4.65 & .60 & 4.73 & .76 & 4.72 & .64 & 4.86 & .57 & 5.08 & .54 & .019 & $1<5$ \\
\hline Self-acceptance & 3.89 & .65 & 4.09 & .56 & 3.99 & .49 & 4.13 & .65 & 4.32 & .74 & .004 & $1<5$ \\
\hline
\end{tabular}

\section{Gender Differences}

Although women score is higher on Self-transcendence than men, their score is significantly lower on Self-Enhancement and Self-acceptance than men (Table 2). 
Table 2. Gender differences on target variables.

\begin{tabular}{cccccccc}
\hline \multirow{2}{*}{ Variables } & \multicolumn{2}{c}{ Male } & \multicolumn{2}{c}{ Female } & \multirow{2}{*}{$\boldsymbol{N}$} & $\boldsymbol{p}$ \\
\cline { 2 - 5 } & $\boldsymbol{M}$ & $\boldsymbol{S D}$ & $\boldsymbol{M}$ & $\boldsymbol{S} \boldsymbol{D}$ & & \\
\hline Self-Transcendence & 24.2 & 3.85 & 25.6 & 2.70 & -3.22 & .002 \\
Self-Enhancement & 10.8 & 2.96 & 10.1 & 2.87 & 2.18 & .030 \\
Self-Acceptance & 4.1 & 0.56 & 3.9 & 0.65 & 1.81 & .050 \\
\hline
\end{tabular}

Basic Values and Dependent Variables

As Table 3 shows, growth-oriented basic value systems, which are relatively free of anxiety systems, are positively associated with Psychological Flexibility as well as with Unconditional Self-acceptance. Namely, Self-transcendence positively correlated with Psychological Flexibility and Unconditional Self-acceptance. Similarly, Openness to Change strongly and positively associated with Psychological Flexibility and Unconditional Self-acceptance. Also, it should be noted that Unconditional Self-acceptance and Psychological Flexibility were interconnected.

Besides, Self-enhancement weakly and negatively associated with Unconditional Selfacceptance and weakly positively connected to Psychological Flexibility.

The Table 3 also shows that basic value systems are interconnected. Namely, Self-transcendence positively correlates with Readiness to Change and conservation, whilst there is a positive correlation between Self-enhancement value system and Openness to Change.

Table 3. Basic value systems and dependent variables.

\begin{tabular}{lcccccc}
\hline \multicolumn{1}{c}{ Variable } & $\mathbf{1}$ & $\mathbf{2}$ & $\mathbf{3}$ & $\mathbf{4}$ & $\mathbf{5}$ & $\mathbf{6}$ \\
\hline Self-transcendence & - & & & & & \\
Self-enhancement & .06 & - & & & & \\
Openness to change & $.45^{* *}$ & $.46^{* *}$ & - & & & \\
Conservation & $.61^{* *}$ & $.12^{*}$ & $.18^{* *}$ & - & & \\
Unconditional self-acceptance & $.12^{*}$ & $-.10^{*}$ & $.13^{*}$ & -.03 & - & \\
Psychological flexibility & $.45^{* *}$ & $.14^{* *}$ & $.52^{* * *}$ & $.3^{* *}$ & $.24^{* * *}$ & - \\
\hline$N$ & 365 & 366 & 368 & 367 & 364 & 364 \\
$M$ & 25.21 & 10.29 & 18.79 & 23.13 & 4.00 & 4.73 \\
SD & 3.12 & 2.90 & 2.70 & 3.49 & .631 & .655 \\
\hline
\end{tabular}

Note: ${ }^{*} p \leq .05 ;{ }^{* *} p \leq .01 ;{ }^{* * *} p \leq .001$

Correlation analysis, thus, suggests that basic values systems correlated with Psychological Flexibility and Self-acceptance. Growth-oriented values positively associated with both, Psychological Flexibility and Unconditional Self-acceptance. However, Psychological Flexibility showed positive relationships with other value systems too, such as Conservation and Self-enhancement. In order to see whether target value systems possess predictive power independently from each other, while controlling the rest of the systems, multiple hierarchical regression was applied. 
The first regression model for Unconditional self-acceptance, (Table 4) includes Selfenhancement and Conservations variables, which, as seen from the graph, has no predictive value. Nevertheless, when Self-transcendence and Readiness to Change were added to the model (Step 2$)$, the model explains only $5.8 \%$ of variability $\left(R^{2}=.058, F(4,360)=5.501, p \leq .001\right)$. As for independent value of the variables, Openness to Change possesses positive predictive value, whilst Self-enhancement and Conservations shows negative predictive power. Although, Self-transcendence and Self-acceptance are correlated, in the whole model Self-transcendence cannot predict Self-acceptance.

Table 4. Hierarchical regression of Unconditional Self-acceptance on basic value systems.

\begin{tabular}{lccccccc}
\hline & $B$ & $S E$ & $\beta$ & $R$ & $R^{2}$ & $\Delta R$ & $\operatorname{sig} \Delta R$ \\
\hline Step 1 & & & & .098 & .010 & .010 & \\
$\quad$ & -.020 & .011 & -.092 & & & & \\
$\quad$ Self-enhancement & -.004 & .009 & -.024 & & & &
\end{tabular}

Step 2

$.240 \quad .058 \quad .048 \quad .0001$

\begin{tabular}{lccc} 
Self-enhancement & -.036 & .013 & $-.165^{* *}$ \\
Conservation & -.023 & .012 & $-.129^{*}$ \\
Self-transcendence & .028 & .015 & .137 \\
Openness to change & .039 & .015 & $.168^{* *}$ \\
\hline
\end{tabular}

Note: ${ }^{*} p \leq .05 ;{ }^{* *} p \leq .01 ;{ }^{* * *} p \leq .001$

As Table 5 shows (Step 1), the values of Self-enhancement and Conservation explain 10\% of variability $\left(R^{2}=.097, F(2,362)=19.4, p \leq .001\right)$. As for independent value of each of the variables, conservation has the biggest weight in total score on Psychological Flexibility.

Table 5. Hierarchical regression of Psychological Flexibility on basic value systems.

\begin{tabular}{lccccccc}
\hline & $B$ & $S E$ & $\beta$ & $R$ & $R 2$ & $\Delta R$ & $\operatorname{sig} \Delta R$ \\
\hline Step 1 & & & & .311 & .097 & .097 & \\
$\quad$ Self-enhancement & .023 & .011 & $.103^{*}$ & & & & \\
$\quad$ Conservation & .053 & .009 & $.281^{* *}$ & & & &
\end{tabular}

Step 2

$\begin{array}{lccc}\text { Self-enhancement } & -.022 & .011 & -.098^{*} \\ \text { Conservation } & .019 & .010 & .104 \\ \text { Self-transcendence } & .041 & .013 & .197^{* * *} \\ \text { Openness to change } & .110 & .013 & .457^{* * *}\end{array}$


By adding Self-transcendence and Openness to Change on the second step of analysis, the model explains $24 \%$ more variability and this change is statistically significant $\left(R^{2}=.339, F(4,362)\right.$ $=46.21, p \leq .001)$. As for predictive values of each of the variables, it turned out that Openness to Change has the higher value in the model $(\beta=.457, p \leq .001)$. Besides, Self-transcendence has relatively less but statistically significant predictive value $(\beta=.197, p \leq .001)$.

Considering both models of hierarchical multiple regression, mediation model was applied (Hayes, 2012). The relationship between Openness to Change and Unconditional Self-acceptance is mediated by Psychological Flexibility (Figure 1). Unstandardized regression coefficient between Openness to Change is statistically significant, as is unstandardized regression coefficient between Psychological Flexibility and Unconditional Self-acceptance.

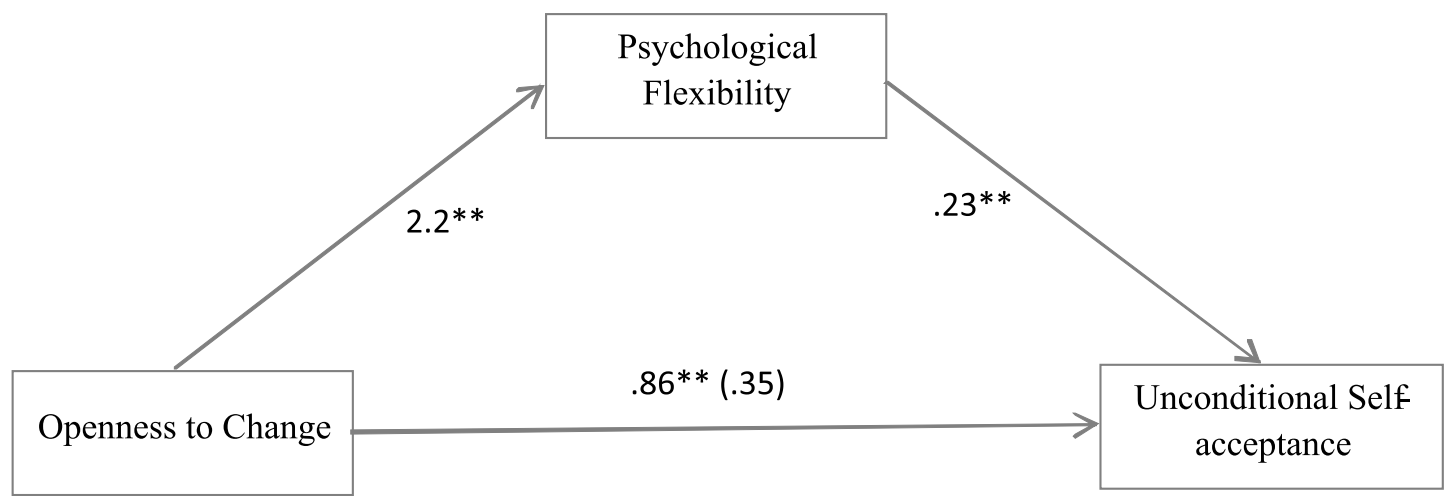

Note: In performing mediation analyses, rest of the basic value systems was controlled. ${ }^{* *} p \leq .01$.

Figure 1. Relationship between Openness to Change and Unconditional Selfacceptance mediated by Psychological Flexibility.

\section{Discussion}

The aim of the research was to explore the connection between basic value systems and Unconditional Self-acceptance, and to establish the role of Psychological Flexibility in this connection.

First, revealed age and gender differences should be discussed. The scores on values of Openness to Change and Conservation differed according to age groups of research participants, that is logical if consider less tendency to admiration absolutes in younger age and being more open to new experiences as younger people have not formulated unquestionable opinions yet (Allemand \& Lehmann, 2012). With age human beings become more attached to their habit patterns and less open to new and different stimuli and challenges in outer world (Glen, 1974). This nicely corresponds to the study (Schwarz, 2012), which showed that as person grows older, her/his values of Conservation strengthen, whilst values of Openness to Change decrease.

Further, research participants beyond 56 scored higher on Psychological Flexibility and Self-acceptance than participants from the youngest age group (18-25). These results nicely correspond to the existing findings that emotional well-being improves, i.e. negative affect decreases as age increases (Charles \& Piazza, 2009; Cheng, 2004; Mather \& Carstensen, 2005). It should be noted that, when defining construct of acceptance, researchers focus on voluntary and nonjudgmental process of involvement in negative emotions. This process, in turn, supports better understanding of emotions (Segal, Williams, \& Teasdale, 2002). With high levels of acceptance one does not avoid negative emotions, which in turn helps to decrease negative affect (Campbell-Sills, Barlow, Brown, \& Hofmann, 2006a; Ma \& Teasdale, 2004; Twohig et al., 2010). Contrary to the strategies for the regulation of other emotions, acceptance is based not only on cognitive abilities, which usually declines with age (Schloss \& Haaga, 2011).

Other studies that focus on connection between acceptance and age, targeting wisdom, 
OF PSYCHOLOGY

IN THE $21^{\text {st }}$ CENTURY Vol. 13, No. 2, 2019

94

conceptualized as the experience and knowledge of life (Baltes \& Smith, 2008). The main characteristic of the wisdom is associated with the acceptance of uncertainty, unpredictability and negative emotions, which, in general is linked to the life events (Ardelt, 2000).

According to the results, women scored higher on Self-transcendence value system than men, whilst the latter had higher score on Self-enhancement. If cultural and social context considered, gender differences were expected, as functions, roles, perceptions of gender roles and even biological dispositions differ dramatically. Women are assigned more caring, empathetic gender role, while men are perceived as more achievement and power oriented (Klein \& Hodges, 2001).

These results correspond to existing research. Various theories on gender differences suggest that men are more agentic-instrumental values, such as power and achievement, whilst women are more prone towards expressive-communal values, such as benevolence and universalism (Schwartz \& Rubel, 2005). Observed gender differences might be explained by employing evolutionally theory as well as social role theory. Both theories suggest that the existing differences stem from adaptation with environment (Schwartz \& Rubel, 2005).

It is quite difficult to find the direct connection between Self-acceptance and gender in existing research, however, aggregating cross-sectional studies state that men have higher self-esteem than women (Huang, 2010; Kling, Hyde, Showers, \& Buswell, 1999.; Orth \& Robins, 2014; Robins \& Trzesniewski, 2005; Trzesniewski, Donnellan, \& Robins, 2013). Since Self-esteem and Self-acceptance share conceptual commonalities (Macinnes, 2006), we can bring our data in compliance with existing body of research.

As expected, anxiety-free values were associated with higher score on Self-acceptance and Psychological Flexibility: unconditional self-acceptance was positively associated with selftranscendence and openness to change, while it associated negatively with self-enhancement. As noted, self-transcendence and openness to change are anxiety-free values (Schwartz, 2012), whilst high anxiety might be associated with various life difficulties, misperception of oneself and environment included (Davies, 2007).

Further, all four value systems positively correlated with psychological flexibility, which can be explained by referring on their own structure and ranging according their importance (Schwartz, 2010). Accordingly, there is no isolated value system or distinct value. As the rule, they function interconnectedly and in relation to each other. It should be noted that much stronger association was revealed in case of self-transcendence and openness to change or, in other words, growth-oriented values.

Since psychological flexibility statistically significantly correlated with all four value systems, to establish predictive value of individual value, multiple hierarchical regression was performed. The model was constructed based on primary assumption that anxiety-free and growth-oriented values should serve as the basis for psychological flexibility. On the first step, conservation and self-enhancement were included in the model, which showed some predictive value, however, after adding self-transcendence and openness to change on the second step, the predictive value of the model significantly improved, coefficient for self-enhancement turned to negative. This means that when all value systems are considered, unique contribution of self-enhancement in the model is negative. Besides, it is worth to mention that conservation values lost its predictive value. To sum up, if all value systems are considered, only openness to change and self-transcendence possess positive predictive value for psychological flexibility. These results complement existing knowledge that individuals open to experience are more flexible, adaptive and open to novelties (Higgins, 2006; King \& Hicks, 2007; Kashdan \& Silvia, 2009).

As for self-acceptance, we assumed that anxiety-free values should reliably predict higher level of unconditional self-acceptance. On the first step of the analysis two value systems (selfenhancement and conservation) were controlled. Each of them independently had no predictive power for self-acceptance. However, when self-transcendence and openness to change were added to the equation on the second step, we found that each of two controlled variables were reliable negative predictors, whilst openness to change positively predicted outcome variable. The final model suggests that self-transcendence did not possess predictive value. This means that of basic value systems only openness to change predicts higher score of unconditional 
self-acceptance, and self-enhancement and conservation, when controlling for other value systems, is reflected on lower score of self-acceptance. These results come into compliance and complement tolerance research, which focuses on increased acceptance of various experiences and individuals (Dimidjian \& Linehan, 2009; Wlliams \& JayLynn, 2010).

Based on regression models, we claim that anxiety-free basic value systems are connected to the degree of flexibility of the individual's mental resources and the ability to consider various contexts and adjust accordingly. Further, we found that off explored value systems only openness to change possesses unique predictive value for unconditional self-acceptance, whilst self-enhancement and conservation, i.e. full of anxiety and self-protective values negatively reflected on self-acceptance.

As for the main research question: whether psychological flexibility explains correlation between values and self-acceptance? We assumed that anxiety-free values should push individuals to be more involved in various situations and events, and to accept difference experiences, which, in turn, is manifested in higher level of flexibility. The latter enhance self-acceptance.

To test this hypothesis, we constructed mediation model where the value system of openness to change was major independent variable based on the rational that it was only variable with independent predictive values for self-acceptance. As data shows, openness to changes reflects on higher score of self-acceptance through psychological flexibility. In other words, individual with such a value system is better able to consider various aspects of the environment, to gain different experiences, to proper distribute and redirect her/his own mental resources. That is how the individual manages to accept herself/himself entirely.

\section{Conclusions}

The presented research was aiming at revealing the connection between individual's basic values and unconditional self-acceptance and exploring the impact of psychological flexibility on this association. It was assumed, that anxiety-free and growth-oriented value systems should be positively reflected on unconditional self-acceptance through psychological flexibility.

Final model suggested that value systems of Self-transcendence and Openness to change predict higher level of Psychological Flexibility, however, only Openness to change possessed positive predictive power for Unconditional self-acceptance.

Mediation model indicates that basic value system of openness to changes is the one, which reflected on individual's higher psychological flexibility, and through this flexibility she/ he achieves higher level of unconditional self-acceptance.

The research, on the one hand, supports and confirms the main idea of existing research flexibility is important factor for self-acceptance - however, it has been established that there is significant connection between Unconditional Self-acceptance and Basic Value systems and most importantly, the unique role of Openness to change for building Unconditional Selfacceptance has been revealed. It has been found, that one-way Openness to change affects Unconditional Self-acceptance is through increasing Psychological Flexibility.

Therefore, the main finding of the study - confirmed unique role of openness to change in association with self-acceptance - may serve as important insight for clinical psychologists as well as for mental health professionals.

\section{Limitations of the research}

Despite its contributions, this research has certain limitations: This study relies solely on the samples from convenience method, which decreases feasibility of generalizing. Other than this, gender and age distribution in the sample does not give us validation to make assumptions based solely on this sample.

For further research, it would be interesting to see the impact and contribution of individual values in Unconditional self-acceptance and see how they are functioning in relation to each other. 
OF PSYCHOLOGY

IN THE $21^{\text {st }}$ CENTURY

Vol. 13, No. 2, 2019

\section{Acknowledgments}

The research was supported by structured PhD Programme in Positive Psychology, granted by Shota Rustaveli National Science Foundation of Georgia, the main foundation, supporting the development of Science, Technology and Innovation in Georgia (Grand number: DP2016_16).

\section{References}

Allemand, M., \& Lehmann, R. (2012). Personality development and aging. In V. S. Ramachandran (Eds.), Encyclopedia of human behavior (pp. 74-81). San Diego, CA: Elsevier.

Ardelt, M. (2000). Antecedents and effects of wisdom in old age: A longitudinal perspective on aging well. Research on Aging, 22, 360-394.

Baer, R. A. (Ed.). (2006). Mindfulness-based treatment approaches: Clinician's guide to evidence base and applications. San Diego, CA: Elsevier

Baltes, P. B., \& Smith, J. (2008). The fascination of wisdom: Its nature, ontogeny, and function. Perspectives on Psychological Science, 3, 56-64.

Bardi, A., \& Schwartz, S. H. (2003). Values and behavior: Strength and structure of relations. Personality and Social Psychology Bulletin, 29, 1207-1220.

Batson, C. D., Eklund, J. H., Chermok, V. L, Hoyt, J. L, \& Ortiz, B. G. (2007). An additional antecedent of empathic concern: Valuing the welfare of the person in need. Journal of Personality and Social Psychology, 93, 65-74.

Beck, A. T., Emery, G., \& Greenberg, R. L. (1996). Cognitive therapy for evaluation anxieties. Handbook of the Treatment of the Anxiety Disorders, 235-260.

Ben-Itzhak, S, Bluvstein, I., \& Maor, M. (2014). The Psychological Flexibility Questionnaire (PFQ): Development, Reliability and Validity. WebmedCentral PSYCHOLOGY, 5(4), WMC004606. Retrieved from https://pdfs.semanticscholar.org/eac5/3d0f5898843a0d8c60723f456a16a510b727.pdf.

Bonanno, G. A., Papa, A., Lalande, K., Westphal, 4. M., \& Coifman, K. (2004). The Importance of Being Flexible The Ability to Both Enhance and Suppress Emotional Expression Predicts Long-Term Adjustment. Psychological Science, 15(7), 482-487

Brown, L. (Ed.). (1993). The Oxford shorter English dictionary. New York: Oxford University Press.

Campbell-Sills L, Barlow D. H., Brown T. A., \& Hofmann S. G. (2006b). Acceptability and suppression of negative emotion in anxiety and mood disorders. Emotion, 6, 587-595.

Caprara, G. V., \& Steca, P. (2007). Prosocial agency: The contribution of values and self-efficacy beliefs to prosocial behavior across ages. Journal of Social and Clinical Psychology, 26(2), 218-239. https://doi. org/10.1521/jscp.2007.26.2.218.

Carson, S. H., \& Langer, E. J. (2006). Mindfulness and self-acceptance. Journal of Rational-Emotive \& CognitiveBehavior Therapy, 24(1), 29-43. https://doi.org/10.1007/s10942-006-0022-5.

Chamberlain, J. M., \& Haaga, D. A. F. (2001). Unconditional self-acceptance and psychological health. Journal of Rational-Emotive and Cognitive-Behavior Therapy, 19, 163-176.

Chamorro-Premuzic, T., \& Reichenbacher, L. (2008). Effects of personality and threat of evaluation on divergent and convergent thinking. Journal of Research in Personality, 42, 1095-1101.

Charles, S. T., Piazza J. R. (2009). Age differences in affective well-being: Context matters. Social and Personality Psychology Compass, 3, 711-724.

Chawla, N., \& Ostafi n, B. D. (2007). Experiential avoidance as a functional dimensional approach to psychopathology: An empirical review. Journal of Clinical Psychology, 63, 871-890.

Cheng, S. T. (2004) Age and subjective well-being revisited: A discrepancy perspective. Psychology and Aging, 19, 409-415.

Cook, D., \& Hayes, S. C. (2010). Acceptance-based coping and the psychological adjustment of Asian and Caucasian Americans. International Journal of Behavioral Consultation and Therapy, 6, 186-197. 
Cordova, J. V., \& Kohlenberg, R. J. (1994). Acceptance and the therapeutic relationship. In S. C. Hayes, N. S. Jacobson, V. M. Follette, \& M. J. Dougher (Eds.), Acceptance and change: Content and context in psychotherapy (pp. 125-142). Reno, NV: Context Press.

DeYoung, C. G. (2006). Higher-order factors of the Big Five in a multi-informant sample. Journal of Personality and Social Psychology, 91(6), 1138-1151. https://doi.org/10.1037/0022-3514.91.6.1138.

Dimidjian, S., \& Linehan, M. M. (2003). Defining an agenda for future research on the clinical application of mindfulness practice. Clinical Psychology: Science and Practice, 10(2), 166171.

Dryden, W., \& Neenan, M. (2004). Rational emotive behavioural counselling in action. Retrieved from https:// books.google.ge/books?id=zKsd8i8DO2wC.

Ellis, A. (1997) Extending the goals of behavior therapy and cognitive behavior therapy. Behavior Therapy, 28(3), 333-339

Ellis, A., \& Robb, H. (1994). Acceptance in rational-emotive therapy. In S. C. Hayes, N. S. Jacobson, V. M. Follette and M. J. Dougher (Eds.), Acceptance and change: Content and context in psychotherapy (pp. 13-32). Reno, NV: Context Press.

Ellis, A., David, D., \& Lynn, S. J. (2010). Rational and irrational beliefs: A historical and conceptual perspective. In D. David, S. J. Lynn, \& A. Ellis (Eds.), Rational and irrational beliefs: Research, theory, and clinical practice (pp. 3-22). New York, NY, US: Oxford University Press.

Falkenstein, M. J., \& Haaga, D. A. F. (2013). Measuring and characterizing unconditional self-acceptance. In Michael E. Bernard (Ed.), The strength of self-acceptance (pp. 139-151). https://doi.org/10.1007/9781-4614-6806-6_9.

Follette, V. M., \& Pistorello, J. (2007). Finding life beyond trauma: Using acceptance and commitment therapy to heal from post-traumatic stress and trauma-related problems. Oakland, CA: New Harbinger.

Fruzzetti, A. E., \& Iverson, K. M. (2004). Mindfulness, acceptance, validation, and "individual” psychopathology in couples. In S. C. Hayes, V. M. Follette and M. M. Linehan (Eds.), Mindfulness and Acceptance (pp. 66-95). New York: Guilford.

Galatzer-Levy, I. R., Burton, C. L., \& Bonanno, G.13. A. (2012). Coping flexibility, potentially traumatic life events, and resilience: A prospective study of college student adjustment. Journal of Social and Clinical Psychology, 31(6), 542-567.

Geertz, C. (1973). The interpretation of cultures. New York: Basic Books

Germer, C. K. (2005). Mindfulness. In C. K. Germer, R. D. Siegel \& P. R. Fulton (Eds.), Mindfulness and psychotherapy (pp. 3-27). New York: Guilford.

Glen, N. D. (1974). Aging and conservatism. Annals of the American Academy of Political and Social Science, 415, 176-186.

Greenberg, L., \& Safran, J. D. (1987). Emotion in psychotherapy. New York: Guilford. Bulletin, 28, 789-801.

Hayes, S. C. (1994a). Content, context, and the types of psychological acceptance. In S. C. Hayes, N. S. Jacobson, V. M. Follette, \& M. J. Dougher (Eds.), Acceptance and change: Content and context in psychotherapy (pp. 13-33). Reno, NV: Context Press.

Hayes, S. C. (2004). Acceptance and commitment therapy, relational frame theory, and the third wave of behavioral and cognitive therapies. Behavior Therapy, 35(4), 639-665. https://doi.org/10.1016/S00057894(04)80013-3.

Hayes, S. C. (2004a). Acceptance and Commitment Therapy and the new behavior therapies: Mindfulness, acceptance, and relationship. In S. C. Hayes, V. M. Follette and M. M. Linehan (Eds.), Mindfulness and acceptance (pp. 1-29). New York: Guilford.

Hayes, S. C., Follette, V. M., \& Linehan, M. M. (Eds.). (2011). Mindfulness and acceptance: Expanding the cognitive-behavioral tradition. New York: Guilford Press.

Hayes, S. C., Luoma, J., Bond, F., Masuda, A., \& Lillis, J. (2006). Acceptance and commitment therapy: Model, processes, and outcomes. Behaviour Research and Therapy, 44, 1-25.

Hayes, S. C, Strosahl, K. D., \& Wilson, K. G. (2012). Acceptance and commitment therapy: The process and practice of mindful change (2nd edition). New York, NY: The Guilford Pres. 
OF PSYCHOLOGY

IN THE $21^{\text {st }}$ CENTURY Vol. 13, No. 2, 2019

98

Helson, R., \& Srivastava, S. (2001). Three paths of adult development: Conservers, seekers, and achievers. Journal of Personality and Social Psychology, 80, 995-1010.

Hibbing, J. R., Smith, K. B., \& Alford, J. R. (2014). Differences in negativity bias underlie variations in political ideology. Behavioral and Brain Sciences, 37(3), 297-307. https://doi.org/10.1017/S0140525X13001192.

Higgins, E. T. (2006). Value from hedonic experience and engagement. Psychological Review, 113(3), 439-460. https://doi.org/10.1037/0033-295X.113.3.439.

Huang, C. (2010). Mean-Level change in self-esteem from childhood through adulthood: Meta-Analysis of longitudinal studies. Review of General Psychology, 14(3), 251-260. https://doi.org/10.1037/a0020543.

Izard, C. E. (1977). Human emotions. New York: Plenum.

Jost, J. T., Glaser, J., Kruglanski, A. W., \& Sulloway, F. J. (2003). Political conservatism as motivated social cognition. Psychological Bulletin, 129(3), 339-375.

Kashdan, T. B., \& Silvia, P. (2009). Curiosity and interest: The benefits of thriving on novelty and challenge. In S. J. Lopez, \& C. R. Snyder (Eds.), Oxford handbook of positive psychology (pp. 367-374). 2nd Ed. New York, NY.

Kashdan, T. B., \& Rottenberg, J. (2010). Psychological flexibility as a fundamental aspect of health. Clinical Psychology Review, 30(7), 865-878.

King, L. A., \& Hicks, J. A. (2007). Whatever happened to "what might have been"? Regret, happiness, and maturity. American Psychologist, 62, 625-636.

Klein, K. J., \& Hodges, S. D. (2001). Gender differences, motivation, and empathic accuracy: When it pays to understand. Personality and Social Psychology Bulletin, 27(6), 720-730.

Kling, K. C., Hyde, J. S., Showers, C. J., \& Buswell, B. N. (1999). Gender differences in self-esteem: A metaanalysis. Psychological Bulletin, 125(4), 470-500.doi:10.1037/0033-2909.125.4.470.

Klohnen, E. C. (1996). Conceptual analysis and measurement of the construct of egoresiliency. Journal of Personality and Social Psychology, 70, 1067-1079.

Kruglanski, A. W., \& Webster, D. M. (1996). Motivated closing of the mind: "Seizing"and "freezing". Psychological Review, 103, 263-283.

Landstra, J., Ciarrochi, J., Deane, F. P., \& Hillman, R. J. (2013). Identifying and describing feelings and psychological flexibility predict mental health in men with HIV. British Journal of Health Psychology, 18(4), 844-857. doi: 10.1111/bjhp.12026.

Lönnqvist, J-E., Verkasalo, M., Wichardt, P. C., and Walkowitz. G. (2013). Personal values and prosocial behaviour in strategic interactions: Distinguishing value-expressive from value-ambivalent behaviours. European Journal of Social Psychology, 43, 554-569.

Ma, S. H., \& Teasdale, J. D. (2004). Mindfulness-based cognitive therapy for depression: Replication and exploration of differential relapse prevention effects. Journal of Consulting and Clinical Psychology, 72(1), 31-40.

Macinnes, D. L. (2006). Self-esteem and self-acceptance: An examination into their relationship and their effect on psychological health: Self-esteem and self-acceptance. Journal of Psychiatric and Mental Health Nursing, 13(5), 483-489. https://doi.org/10.1111/j.1365-2850.2006.00959.x

Mather, M., \& Carstensen, L. L. (2005) Aging and motivated cognition: The positivity effect in attention and memory. Trends in Cognitive Sciences, 9, 496-502.

Matsumoto, D., LeRoux, J. A., Robles, Y., \& Campos, G. (2007). The Intercultural Adjustment Potential Scale (ICAPS) predicts adjustment above and beyond personality and general intelligence. International Journal of Intercultural Relations, 31, 747-759.

McCrae, R. R., \& Costa, P. T. (1997). Conceptions and correlates of openness to experience. In R. Hogan, J. Johnson \& S. Briggs (Eds.), Handbook of personality psychology (pp. 825-847). San Diego: Academic Press.

McCracken, L. M., Gutiérrez-Martínez, O., \&26. Smyth, C. (2013). "Decentering” Reflects Psychological Flexibility in People with Chronic Pain and Correlates With Their Quality of Functioning. Health Psychology, 32(7), 820-823. 
Mikulincer, M., Gillath, O., Sapir-Lavid, Y., Yaakobi, E., Arias, K., Tal-Aloni, L., \& Bor, G. (2003). Attachment theory and concern for others' welfare: Evidence that activation of the sense of secure base promotes endorsement of self-transcendence values. Basic and Applied Social Psychology, 25, 299-312.

Nolen-Hoeksema, S., Wisco, B. E., \& Lyubomirsky, S. (2008). Rethinking rumination. Perspectives on Psychological Science, 3(5), 400-424.

O'Brien, T. B., \& DeLongis, A. (1996). The interactional context of problem-, emotion-, and relationship-focused coping: The role of the Big Five personality factors. Journal of Personality, 64, 775-813.

Orth, U., \& Robins, R. W. (2014). The development of self-esteem. Current Directions in Psychological Science, 23(5), 381-387. https://doi.org/10.1177/0963721414547414.

Peterson, R. F. (1994). Acceptance, experience, and choice. In S. C. Hayes, N. S. Jacobson, V. M. Follette and M. J. Dougher (Eds.), Acceptance and change: Content and context in psychotherapy (pp. 13-32). Reno, NV: Context Press.

Piurko, Y., Schwartz, S.H., and Davidov, E. (2011). Basic personal values and the meaning of left-right political orientations in 20 countries. Political Psychology, 32, 537-561.

Robins, R. W., \& Trzesniewski, K. H. (2005). Self-esteem development across the lifespan. Current Directions in Psychological Science, 14(3), 158-162. https://doi.org/10.1111/j.0963-7214.2005.00353.x.

Roccas, S., Sagiv, L., Schwartz, S. H., \& Knafo, A. (2002). The big five personality factors and personal values. Personality and Social Psychology Bulletin, 28(6), 789-801. https://doi.org/10.1177/0146167202289008.

Rokeach, M. (1973). The nature of human values. New York: Free Press.

Ruiz, F. J. (2012). Acceptance and commitment therapy versus traditional cognitive behavioral therapy: A systematic review and meta-analysis of current empirical evidence. International Journal of Psychology, 12(3), 333-357.

Sagiv, L., \& Schwartz, S. H. (2000). Value priorities and subjective well-being: Direct relations and congruity effects. European Journal of Social Psychology, 30, 177-198.

Schwartz, S. H. (1992). Universals in the content and structure of values: Theory and empirical tests in 20 countries. In M. P. Zanna (Ed.), Advances in experimental social psychobgy (Vol. 25, pp. 1-65). New York: Academic Press.

Schwartz, S. H. (2012). An overview of the Schwartz Theory of Basic Values. Online Readings in Psychology and Culture, 2(1). https://doi.org/10.9707/2307-0919.1116.

Schwartz, S. H. (2014). Negativity bias and basic values. Behavioral and Brain Sciences, 37(3), 328-329. doi: $10.1017 / \mathrm{s} 0140525 \times 13002720$.

Schwartz, S. H., Sagiv, L., \& Boehnke, K. (2000). Worries and values. Journal of Personality, 68, 309-346.

Schwartz, S. H., \& Rubel, T. (2005). Sex differences in value priorities: Cross-cultural and multi-method studies. Journal of Personality and Social Psychology, 89(6), 1010-1028. https://doi.org/10.1037/00223514.89.6.1010.

Schloss, H. M., \& Haaga, D. A. F. (2011). Interrelating behavioral measures of distress tolerance with selfreported experiential avoidance. Journal of Rational-Emotive \& Cognitive Behavior Therapy, 29, 53-63.

Segal, Z. V., Williams, J. M. G., \& Teasdale, J. D. (2002). Mindfulness-based cognitive therapy for depression: A new approach to preventing relapse. New York: Guilford Press.

Silfver, M., Helkama, K., Lonnqvist, J.-E., \& Verkasalo, M. (2008). The relation between value priorities and proneness to guilt, shame, and empathy. Motivation and Emotion, 32, 69-80.

Sloan, D. M. (2004). Emotion regulation in action: Emotional reactivity in experiential avoidance. Behavior Research and Therapy, 42, 1257-1270.

Sorrentino, R. M., \& Roney, C. R. J. (2000). The uncertain mind: Individual differences in facing the unknown. Philadelphia: Psychology Press.

Stankovic, S., Matic, M., Vukosavljevic-Gvozden, T., \& Opacic, G. (2015). Frustration intolerance and unconditional self-acceptance as mediators of the relationship between perfectionism and depression. Psihologija, 48(2), 101-117. https://doi.org/10.2298/PSI1502101S. 
Thoits, P. A., \& Hewitt, L. N. (2001). Volunteer work and well-being. Journal of Health and Social Behavior, 42(2), 115. https://doi.org/10.2307/3090173.

Thompson, B. L., \& Waltz, J. A. (2008). Mindfulness, self-esteem, and unconditional self-acceptance. Journal of Rational-Emotive \& Cognitive-Behavior Therapy, 26(2), 119-126. https://doi.org/10.1007/s10942007-0059-0.

Tritt, S. M., Inzlicht, M., \& Peterson, J. B. (2014). Confounding valence and arousal: What really underlies political orientation? Behavioral and Brain Sciences, 37(03), 330-331. doi:10.1017/s0140525x13002744.

Trzesniewski, K., Donnellan, B., \& Robins, R. W. (2013). Development of self-esteem. In V. Zeigler-Hill (Ed.), Self-esteem (pp. 60 -79). New York, NY: Psychology Press.

Twohig, M. P., Hayes, S. C., Plumb, J. C., Pruitt, L. D., Collins, A. B., Hazlett-Stevens, H., \& Woidneck M. R. (2010). A randomized clinical trial of acceptance and commitment therapy vs. progressive relaxation training for obsessive compulsive disorder. Journal of Consulting and Clinical Psychology, 78,705-716.

Weiner, E. S. C., \& Simpson, J. A. (Eds.). (1991). The compact Oxford English dictionary (2 ${ }^{\text {nd }}$ Ed.). New York: Oxford University Press.

Williams, J., \& Lynn, S. (2010). Acceptance: An historical and conceptual review. Imagination, Cognition and Personality, 30, 5-56. 10.2190/IC.30.1.c.

Received: August 30, 2019

Accepted: December 05, 2019

\begin{tabular}{|c|c|}
\hline Mariam Kvitsiani & $\begin{array}{l}\text { M.Sc., PhD Student, Ivane Javakhishvili Tbilisi State University, } \\
\text { Chavchavadze ave, 11a, Tbilisi, Georgia. } \\
\text { E-mail: Mariam.kvitsiani768@pes.tsu.edu.ge }\end{array}$ \\
\hline Maia Mestvirishvili & $\begin{array}{l}\text { Associate Professor, Department of Psychology, Ivane Javakhishvili Tbilisi } \\
\text { State University, Tbilisi, Georgia. } \\
\text { E-mail: maia.mestvirishvili@tsu.ge }\end{array}$ \\
\hline Khatuna Martskvishvili & $\begin{array}{l}\text { Associate Professor, Deputy Dean of Department of Psychology, Ivane } \\
\text { Javakhishvili Tbilisi State University, Tbilisi, Georgia. } \\
\text { E-mail: khatuna.martskvishvili@tsu.ge }\end{array}$ \\
\hline Tamar Kamushadze & $\begin{array}{l}\text { PhD Student, Department of Psychology, Ivane Javakhishvili Tbilisi State } \\
\text { University, Tbilisi, Georgia. } \\
\text { E-mail: tamar.kamushadze840@pes.tsu.edu.ge }\end{array}$ \\
\hline Mariami Odilavadze & $\begin{array}{l}\text { PhD Student, Department of Psychology, Ivane Javakhishvili Tbilisi State } \\
\text { University, Tbilisi, Georgia. } \\
\text { E-mail: mariami.odilavadze233@pes.tsu.edu.ge }\end{array}$ \\
\hline Mariam Panjikidze & $\begin{array}{l}\text { Associate Professor, Department of Psychology, Ivane Javakhishvili Tbilisi } \\
\text { State University, Tbilisi, Georgia. } \\
\text { E-mail: marika.panjikidze@tsu.ge }\end{array}$ \\
\hline
\end{tabular}

